\title{
Considering Diversity in (Special) Education: Disability, Being Someone and Existential Education
}

\author{
Solveig Magnus Reindal ${ }^{1}$ (D)
}

Accepted: 6 February 2021 / Published online: 19 February 2021

(c) The Author(s) 2021

\begin{abstract}
Discussions on diversity and disability in dialogue with special educationalists and philosophers of education are not often found in the research literature. Researchers within disability studies have been critical towards the enterprise of special education and vice versa, and the language they use is often different, as they draw on various subject fields. In this article, I bring these fields of research together and draw on research from the philosophy of education, special education and Disability Studies. My argument is that a language of diversity needs to be embedded in a language about educational ends and other fundamental questions discussed in the philosophy of education, and not solely in discussions within the field of inclusive education, as is often found in the research literature relating to special education. I argue that the language of diversity related to disability should be embedded in the language of the person, being someone. In order to build my argument, I sketch out three distinctions: disability and impairment, education as cultivation versus an existential education and the distinction between being someone and being something. I argue that an understanding of diversity and the case of disability within the framework of (special) education should preferably be: (1) interpreted within a social relational model of disability, drawing on an adjusted capabilities approach, (2) an existential educational paradigm and (3) seeing the person as someone, and not as something that is associated with a series of facts that happen to relate to what we call persons.
\end{abstract}

Keywords Diversity $\cdot$ Disability $\cdot$ The person $\cdot$ Special education · Existential education

\section{Introduction}

The aim of this article is to investigate the issue of diversity, as it relates to disability, in relation to crucial educational questions, and in so doing, I hope to make a contribution to 'putting persons' back into the educational language of education that Pring (2012) advocates. He criticises education in general for using instrumentalist language and does not specifically mention special education. However, Pring's critique is highly relevant also regarding the field of special education. Discussions on diversity are often addressed in

Solveig Magnus Reindal

SolveigM.Reindal@nla.no

1 NLA University College, Bergen, Norway 
relation to disability and inclusive education, but seldom are the discussions framed within a broader context, reflecting on interpretations of overarching educational ends. It is suggested that the issue of diversity, as it relates to disability, should be examined within the framework of fundamental educational questions. This is addressed by arguing that an understanding of diversity ought to be understood primarily in relation to being a person-to be someone, and not a something like a 'bio-neuro-socio-cultural being', a concept coined by Biesta (2020), in which the human being is interpreted as a coordinate between a system axis and an individual. Understanding the human being in this way rather contributes to a 'depersonalization', of the language in education, as pointed out by Pring (2012). In an effort to create a language that contributes to an understanding of diversity related to disability and resting in a notion of the person, being someone, three important distinctions are sketched out: (1) the distinction between disability and impairment, (2) the paradigm of education as cultivation versus an existential educational paradigm (Biesta 2020) and (3) Spaemann's (2006) distinction between someone and something. Highlighting these three distinctions, I hope to show that the discussions relating to diversity in education ought to be outlined in a language framework other than 'the effective school' and 'science of deliverology' that Pring (2012) has so aptly called the trend in educational thought, emphasizing a target-setting culture that leads to a 'depersonalization' of education. Pring urges us to put the language of persons back into education. This also has implications for the framework of the educational language in which we interpret the issue of diversity as it relates to disability and educational challenges in education. In the following I outline the three aforementioned distinctions.

\section{Diversity-and the Case of Disability in Education Underpinning Educational Challenges}

The impairment/disability distinction has been pivotal in Disability Studies across several decades. The distinction was especially important in developing the social model, by breaking the theoretical causal link between impairment and disability, which was said to underpin the medical interpretations of disability (Oliver 1996, p. 41), and educational practices within special education (Gallagher Heshusius, Iano and Skrtic 2004). A critique of medical and individual models has especially and rightly been addressed by disability scholars. Instead, they interpreted disability as a cultural and social phenomenon caused by social, structural and cultural mechanisms rather than the mere personal effects of impairments (Thomas 2004, 2007). Since then, the debate has evolved around the distinction's social, natural and ontological status (Reindal 2010; Riddle 2013; Terzi 2004; Vehmas and Mäkelä 2009). In the wake of conceptual and theoretical controversies in the field of Disability Studies, the theme disability was increasingly framed in educational discussions, under the heading of diversity, and the term diversity became an important fulcrum in the language of inclusive education (Arnesen et al. 2007) which was also intended to refer not only to disabled children (Kiuppis 2014), but to all school-age children. The slogan 'valuing diversity' almost became a cliché within the literature on inclusive education, increasingly becoming an empty term (Benjamin 2002, p. 310). As the notion 'valuing diversity' evolved, it was criticized for its lack of discernment characteristics. It did not enable teachers and other professionals, according to Benjamin, "to hold on to difference as a means of illuminating present inequalities and imagining radical alternatives" (2002, p. 311). Within the field of Disability Studies, the impairment/disability distinction has also been 
interpreted as a hindrance to valuing diversity. As impairment is defined as a departure of normal functioning, it is argued that one should not relay an understanding of disability on the impairment/disability distinction (Barnes 2016, p. 21). Barnes (2018), therefore, disputes the value of the disability/impairment distinction and argues for a solidaritybased approach to theorizing disability, seeing the term impairment as superfluous to an understanding of disability (p. 1159). Her opinion rests on a specific point of departure. Barnes, explicitly focuses on physical disability in her social philosophy, which does not include psychological and cognitive/intellectual disability (2016, p. 2). However, regarding diversity and the case of disability in education, the whole group of children with various impairments need to be included within a conceptualization of disability. A downplay of the reality of impairment has been criticized by Vehmas and Watson (2016). They argue, that emphasizing solely cultural aspects as characteristics of disability at the expense of the material, will run the risk; "of misconstruing not just the lives of disabled people but also crucial ethical issues" (p. 13). This is especially important regarding inclusive education as is pointed out by Felder (2019). She criticises the use of the term diversity in education as an all-compassing term. Felder argues that to celebrate human diversity per se underestimates both the challenge that disability represents and what it means in the context of education (Felder 2019, p. 3). Felder demonstrates, using various examples, that with regard to disability, diversity is never merely a social reaction to a horizontal element of inequality such as gender, sex, or race but instead "always represents an interactive, complex and dynamic link between these factors and the social and structural environment, as expressed through particular conditions and forms" (p. 11). Children and young people with various social and personal impairment effects, face other challenges in school which cannot just be interpreted in light of social marginalization and discrimination due to gender or skin colour. The effects of some impairments cause specific educational challenges that also need to be dealt with. Felder (2019) holds, that if we are to meet the challenge of inclusive education, the issue of disability must be interpreted not only as "celebrating diversity" but rather as a multidimensional, dynamic and context-bound phenomenon, having the force to address ethical issues and critique social institutions such as the school (p. 13). By highlighting a potential concept that can provide us with an understanding of disability as a multidimensional, dynamic and context-bound phenomenon, able to address ethical issues, Felder (2019) points to an understanding of disability within the capabilities approach (p. 13). I share Felder's view. I hold that an understanding of disability within the framework of the capabilities approach is fruitful regarding an understanding of diversity relating to disability as basis for informing educational challenges in education. I elaborate on the impairment/disability distinction further within this context, using the adjustments that Begon (2017) calls for regarding the capabilities approach. I will discuss this view in the section below.

\section{Diversity Resting on the Distinction between Impairment/Disability-a Social Relational View on Disability Using an Adjusted Capabilities Approach}

The capabilities approach is a political doctrine about basic entitlements that focus on what people actually are able to be and do (Nussbaum 2006, pp. 154, 168). The two main concepts of the approach are 'functioning' and 'capability'. The emphasis is on the capability to function, what a person can do or can be. Capability means opportunity to select, hence 
capabilities have values in and of themselves, as "spheres of freedom and choice", whereas functionings are the "outgrowths or realizations of capabilities" (Nussbaum 2011, p. 25). In the capabilities approach, equality of capability is an essential goal where absence would be connected with a deficit in dignity and self-respect (Nussbaum 2006, p. 292). Functionings can involve quite basic characteristics - such as being well-nourished, being in good health, and receiving an education as well as involving complex activities and states of being - such as having self-respect. Nussbaum identifies a list of central human capabilities, arguing that all of them are implicit in the idea of a life worthy of human dignity. Capabilities are not instrumental to a life of human dignity: "they are understood, instead, as ways of realizing a life of human dignity, in the different areas of life which human beings typically engage" (Nussbaum 2006, p. 161). Disability within such a theoretical framework, is thus understood as a kind of capabilities deprivation due to various differences caused by personal, social, and environmental circumstances.

Previously, I have developed an understanding of disability as a social relational phenomenon as framework for interpreting educational needs (Reindal 2008) within the framework of the capabilities approach developed by Sen $(1992,2009)$ and Nussbaum (2006) using Terzi's (2005ab, 2008, 2009) elaboration of difference as a multidimensional variable (Reindal 2009, 2010). Thomas' (2004, 2007) concept of impairment effect is crucial for an understanding of disability as a social relational phenomenon. Holding on to the central idea in the social model, that disability is more than a person's impairment (Oliver 1996), disability is viewed as additional to the personal and social effect of an impairment (Reindal 2009; Thomas 2007). Whether an impairment is "bad" or just a "mere" difference depends on the personal and social effects of the impairment for that particular person in his/her life as lived experience. How the effect of an impairment is experienced cannot be evaluated a priori but depends upon the life experience of a person. Seeing impairment in this way allows for a value-neutral account of physical and cognitive difference, while at the same time enabling the concept of impairment to play a role in highlighting difference as disadvantageous and identifying what constitutes injustice in the life of people experiencing disability (Begon 2020, p. 21).

With regard to the capabilities approach, diversity is understood as a specific variable consisting of four conditions: personal and environmental characteristics, inter-individual variation and inter-end variation (Sen 1992, p. 85). These various differences constitute a personal profile for every person in relation to the opportunity to develop functionings and capabilities. Whether these differences turn out to be disabling for that particular person, depends on cultural, material, value-related and structural factors-the life experience of that person. In societies in which, for example, a hearing impairment or deafness excludes a child from going to school and being educated, this will render the child disabled in that he or she is hindered in relation to the opportunity to develop important functionings-beings and doings-this will also reduce the capabilities of that child and his/her freedom to choose valued beings and doings. In societies where a child with a hearing impairment receives sign language tuition and/or speech therapy, plus other additional support, that child will experience to be less disabled. This is the task of inclusive education, to facilitate access to education and educational opportunities for every child, although this is not the definitive task of education, as will be elaborated on below.

In an earlier publication (Reindal 2016), I have suggested that Nussbaum's (2006) list of ten capabilities could function as an ethical framework stipulating what inclusion should encompass for every pupil and the school community. Nussbaum's list of ten central human capabilities includes life, bodily health, bodily integrity, the senses, imagination and thought, emotions, practical reason, affiliation (having relationships 
with or living alongside other species) and play and control (political and material) over one's environment (Nussbaum 2011, pp. 33-34). Nussbaum refers to the capabilities in her list as combined capabilities, internal preparation for action and choice, as well as circumstances to exercise that function (Nussbaum 2011, pp. 24-25). For example, if a child with a hearing impairment in the future will have the opportunity to exercise free speech and be safeguarded testimonial justice (Fricker 2017), this not only requires the ability of that child to use a language and his/her ability to cultivate internal capability through development and education, but also the actual material and political circumstances in which that ability can be used. This requires inclusive educational settings, where the child can experience different beings and doings, and is exposed to a variety of opinions, manners and values. That, being said, it is important as Taylor (2012) has pointed out, to ask in which ways the emphasis on achieved functionings will be a reflection of dominant norms and values. Taylor asks "[a]re we justified in requiring certain functionings in children that they will need to achieve adult capability even when this entails an imposition of communicative functioning norms"? (Taylor 2012, p. 119). The problem Taylor points to here is important. She identifies a problem in the capabilities approach when capabilities are defined as capabilities to function. This has more recently been problematized by Begon (2017).

In the article "Capabilities for All?: From Capabilities to Function, to Capabilities to Control', Begon (2017) criticizes Nussbaums's list of capabilities. Begon argues that Nussbaum's reliance on the importance of certain functions and the commitment to the capabilities to perform these functionings, "threatens the neutrality of inclusivity of her approach" (p. 156). It is important for Nussbaum that the capabilities enlisted in her list, should not be interpreted as instrumental in the usual sense of the term but ways of realizing a life with human dignity. Nussbaum's version of the capabilities approach focuses on the protection of areas of freedom, that in her view, are so central that their removal makes a life not worthy of human dignity (2011, p. 31). Dignity, thus for Nussbaum, is not defined prior to or independently of capabilities, but is intertwined with them and their definition (Reindal 2016, p. 8). Nussbaum establishes the centrality of functionings for a dignified life, and then argues that everyone should be entitled to the opportunity to perform them (Begon 2017, p. 163). This move is problematic, as an emphasis on achieved functionings in an educational setting might be informed by dominant norms and values, hence supporting ability expectations in that culture or society (Wolbring 2012). By using asexual persons and persons with impairment effects, such as Autistic Spectrum Conditions (ASC), Begon shows how Nussbaum's list of capabilities can be exclusionary when these capabilities are conceptualized as opportunities to function (p. 164). By citing various elements of Nussbaum's works in relation to different opportunities to function as part of various capabilities, Begon shows that asexual persons and persons with impairment effects, such as ASC, cannot choose to perform the functioning which Nussbaum sees as essential to any dignified life (p. 166). Begon states "we are asking individuals to agree that the ability to perform a functioning of which they are incapable is essential to a dignified life" (p. 166). The case of asexuality, for example, reflects a problem that is different from people choosing celibacy as a life form, as no laws or social stigma prevent people from performing this functioning. The point that Begon wishes to make is that asexual persons, cannot achieve the functioning of sexual satisfaction and so cannot have that capability. Likewise, argues Begon, many people struggling with impairment effects, such as ASC have difficulties in relation to emotional attachments, engaging in social interaction, or imagining the situation of another; "Why should it be a requirement of justice, and a necessary constituent of dignity, that we have an opportunity for a functioning that is unachievable?" (p. 167). 
Could this perhaps unveil an implicit view of ability expectations, a preference for certain abilities (Wolbring 2012) inherent in Nussbaum's capabilities list as capabilities are important, when they contribute to functionings? I believe there is a danger here. Against the background, that Nussbaum conceptualizes capability as the ability to perform valuable functionings, as for example having opportunities for sexual satisfaction as part of bodily integrity (Begon 2017, p. 164) Begon has aptly highlighted a danger, in that Nussbaum's list might implicitly be a driving force of ability expectations. Her list remains perfectionist as long as central capabilities are regarded as representing opportunities to perform those functionings essential for a good life, claims Begon (p. 160). This might encourage discussions relating to cures and enhancement opportunities that are implicitly driven by the expectations to be able to perform valuable functionings. I completely agree with Begon. She has identified an underpinning weakness in the conceptualization of capabilities as opportunities to function. One might ask, whether the capabilities approach, conceptualized as an opportunity to function, would have sufficient ethical resistance with the ever-increasing pressure to develop abilities and opportunities in the wake of technical and genetic innovations, and desires and visions for the future from advocates of enhancements (Buchanan 2011 ab) and transhumanists (Bostrom and Sandberg 2009). However, the demand regarding ability expectations is not independent of how we interpretate what a human being is, and the meaning of personal development. It is for these reasons I argue that an emphasis on existential educational and seeing the person as someone are critical as will be outlined below.

The adjustment Begon argues for, is in my view, welcomed and is significant as it shifts the focus from opportunities to function to the persons own voice and opens a room for resisting what is assumed to be the embedded 'valuable functionings' essential for a dignified life. Begon does not argue for an abolition of Nussbaum's list, rather she suggests an alteration of how capabilities should be conceptualized not to be "understood as opportunities to perform particular functionings, but as opportunities to exercise control in certain domains “ (2017 pp. 155-156). She writes: "Many autistic and asexual individuals would find the suggestion that their life is lacking something 'good and important', and that a cure is an appropriate response to their condition, deeply offensive" (p. 167). I think that this adjustment of the capabilities approach will 'reduce' the danger that Taylor (2012) underlines, namely, the vulnerability of selecting 'abelist preferences' in relation to opportunities to function, which she maintains is prevalent in schooling (p. 118). An example could be the controversy relating to what kind of achieved functionings deaf children or those with a hearing impairment and their parents, are 'encouraged' to strive for (cochlea implants, sign language, oral therapy ${ }^{1}$ ) in order to develop the capabilities of their child and to partake in situations concerning their child's future life. Viewing the task of education as an emphasis on capabilities and an opportunity to exercise control in certain domains, rather than solely focusing on opportunities relating to functionings, might raise the child and parents' awareness of 'abelist preferences' and enable them to choose other options than expected as 'valuable functionings' relating to hearing impairments. An emphasis on being in control opens to select the preferred sensory experience.

To summarize, I argue that the impairment/disability distinction, as developed within the social relational model of disability (Reindal 2008), drawing on the framework of the

\footnotetext{
${ }^{1}$ See Jackie Leach Scully (2012) Deaf identities in disability studies: With us or without us, for an overview of a multifaceted discussion on normativity and culture, regarding the issue of deafness and hearing impairments.
} 
capabilities approach, is a fertile understanding of diversity regarding the issue of disability in education supporting an interpretation of educational needs. Notably, with the adjustment of the capabilities approach, pointed out by Begon (2017), capabilities are conceptualized as opportunities to exercise control in certain domains, rather than as opportunities to function. This adjustment of the capabilities approach is important. It shifts the focus. It has been pointed out that the capabilities approach, with its emphasis on capabilities as opportunities to function, repositions the role of education in the pursuit of human flourishing (Hinchcliffe and Terzi 2009, p. 388). However, there are certain issues with regard to this view of seeing the role of education primarily as the pursuit of human flourishing. It is not untrue per se but it does not capture the whole picture as pointed out by Biesta (2020). A shift to conceptualize capabilities as opportunities to exercise control in certain domains, suggests an emphasis of the subjects' ability to stand forth as an 'I', as the main focus in the capabilities approach which makes it possible to shift the emphasis from an organism that becomes cultivated to a "human individual who exists and stands for the challenge to lead his or her own life", as Biesta sees as the main educational question (p.8). The capabilities approach, seen as an opportunity to function, is in danger of being representative of what Biesta (2020) calls a 'paradigm of cultivation'. I, therefore, believe that the adjustments made by Begon are very important. This leads to the next distinction in which I maintain a language and an understanding of diversity should rest: the distinction between education as a paradigm of cultivation and an existential educational paradigm (Biesta 2020).

\section{Diversity in a Larger Context: Cultivation Versus Existential-a Question of Educational Ends}

Pring (2012) gives many examples of how the language of business and measurement is flooding the 'language' of education. Arts or the 'aesthetics' have been downgraded as a valuable form of knowledge as this kind of insight is difficult to measure (p. 755). Instead, education is dominated by a language of performance management, and target-setting culture, leading to a language of 'depersonalization' in the school environment. He argues that education has become a kind of science of 'deliverology' where teachers shall deliver results by delivering a curriculum (Pring 2012, p. 747). This has led to a failure in respect of what it means to be and grow as a person and is reflected in a narrow conception of successful learning, understood as academic success, claims Pring (2012, p. 755). In my view, Pring highlights a crucial problem relating to the way in which theorizing and educational practices have developed over the last few decades. Likewise, Biesta $(2006,2012)$ has criticized the field of education for emphasizing a language of 'learnification', which shifts the emphasis from education to learning. In a language of learnification, the process of education is described as that of teaching-and-learning, where teachers become facilitators of learning, schools are seen as a learning environment and teaching has been redefined as the creation of learning outcomes (Biesta 2012, p. 583). Biesta, is not against learning as an activity, but learning as a framework for the language which characterizes education. The language of learning does not capture the whole picture. The reason for this critique is that learning, specifically, can take place without an end, thus it is difficult to take responsibility for the direction of learning. According to Biesta, this is why we "need to keep reminding ourselves that education is about education" (2012, p. 584). So, what does Biesta mean by saying that education is about education? Biesta has written extensively on this theme. In the following section, I will use certain elements of his latest work as it specifically links 
to the aforementioned point, relating to the importance of being able to stand forth as an ' $\mathrm{I}$ ', and to the issue of a personalised language in education emphasising the importance of sensing oneself as a person (Pring 2012, p.757).

In the article "Can the prevailing description of educational reality be considered complete? On the Parks-Eichmann paradox, spooky action at a distance and a missing dimension in the theory of education", Biesta (2020) addresses the difference between what he calls a 'paradigm' of education as cultivation, versus an existential educational 'paradigm'. To illustrate the difference between these two paradigms, Biesta uses an example which he claims to be an educational paradox. Two historical persons and cases are used: Rosa Parks, the black woman who refused to give up her seat to a white man in the 'coloured' section of a Montgomery to Alabama bus in 1955 and the Nazi SS-Obersturmbahnfürer Adolf Eichmann, who was convicted of 15 counts of crimes against humanity in his trial in 1961 in Jerusalem. Eichmann admitted to have partaken in the actions but he denied the responsibility, because he was following orders, ${ }^{2}$ while Parks comprehended the signs, 'white forward, coloured rear' but refused to acknowledge the driver's authority to assign seats $^{3}$ (Biesta 2020, p. 3). Biesta explains the paradox in the following way:

The paradox, however, has to do with the fact that what appears as success (Eichmann) or failure (Parks) from the perspective of effective instruction and successful learning- education as qualification and socialisation (see Biesta 2009) - turns out to be the opposite when viewed from what we might term the 'humane' perspective; that is, the perspective of existing-as-subject - education as subjectification. This then raises the question of the exact 'status' of the latter perspective and how it relates to the former (Biesta 2020, p. 3).

Biesta asks us to consider what education is, against the background of what he calls the Parks-Eichmann paradox and the 'status' between the three broad educational ends: qualification, socialization and subjectification. In order to follow Biesta, a precondition is to agree that it is a paradox, when considered from an educational angle. ${ }^{4}$ Biesta makes

\footnotetext{
2 There are several books on the Eichmann trial. Biesta relies on Hannah Arendt's book from 1963 (2020 p. 3), in which Arendt investigates the banalities of evil. In a more recent book, The Eichmann Trial by historian Deborah E. Lipstadt, Arendt's view is criticized with regard to the background of Eichmann's memoir that was released in relation to a trial between Lipstadt and David Irving (a Holocaust denier). Lipstadt says: "In the newly released memoir, Eichmann expressed himself as an inveterate Nazi and anti-Semite. In contrast to claims that would be made by Hannah Arendt that he did not really understand the enterprise in which he was involved, the memoir reveals a man who considered his Nazi leaders to be his "idols" and who was fully committed to their goals" (p. xix) see: Lipstadt, Deborah E. 2011. The Eichmann Trial. Jewish Encounters. New York: Nextbook Schocken.

${ }^{3}$ For a well-documented book on Rosa Parks, see the biography written by Jeanne Theoharis. She documents that the happening on the bus was not the result of a single act, but in line with a life engagement for the rights of black people. Theoharis builds her book on publications and photographs about the life of Rosa Parks that was released to the public in 2015 (p. viii). See: Theoharis, Jeanne. 2015. The Rebellious Life of Mrs. Rosa Parks. Boston: Beacon Press.

${ }^{4}$ As noted in footnote 2 above, the interpretations of Eichmann as a withdrawal of his 'I' under the pretext of following orders, rests on an interpretation of the trial from Arendt's book Eichmann in Jerusalem. A report on the Banality of Evil. One might come to another interpretation of Eichmann if his memoirs were to be the basis of the interpretation of his crimes, as Deborah Lipstadt (2011) claims in her critique of Arendt's interpretation. However, I maintain that Biesta's interpretation can be defended, as his intention is to make an educational point about subjectification, and not a portrayal of the 'true' historical story about Eichmann. It is rather to shed light on the paradox of having educated persons serving an inhuman system. This is powerfully expressed by a school principal who survived World War II: "Dear Teacher: I am a survivor of a concentration camp. My eyes saw what no man should witness: Gas chambers built by learned engineers. Children poisoned by educated physicians. Infants killed by trained nurses. Women and babies
} 
the point, that if education is seen as an intervention that shall bring about preconceived learning outcomes that are culturally embedded, then it seems that Eichmann is successful, as he was assimilated into the social and cultural order at that time, but this was not the case for Parks. In the story about Parks and Eichmann, Biesta 'finds' that Parks stepped forward as an 'I', whereas Eichmann withdrew his 'I'. In discussing whether this is a real educational paradox, Biesta explores whether this is simply a story about different moral choices, and hence has nothing to do with different educational paradigms. He discusses whether the Parks-Eichmann example is just a question of different moral choices and hence does not picture a real educational paradox, but rather a failure of moral education and the cultivation of moral subjects in a particular context. Biesta dismisses this alternative, because ethical and moral judgements need an 'I' to come into play, they require a subject. To bring the 'I' into play and keep the 'I' of the student in play, is according to Biesta, specifically related to an understanding of education as existential, as opposed to education as cultivation (pp. 2,11). A prime example of a paradigm case of an educational theory that promotes and pursues education as 'cultivation' is found, according to Biesta, in the educational theory of Dewey (p. 5). Education as cultivation, is built on an understanding that education relates to the interplay between internal factors and external influences, and describes how individuals become who they are as a result of social and cultural involvement, where the task for education, is to allow children to develop the greatest number of "capacities and capabilities in the fullest way possible" (2020, p. 5). Biesta gives a pointed examination of Dewey's educational theory, and why this educational framework fails to give an understanding of education that foregrounds the question of the 'I'. What is missing in Dewey's theory of education, is that it does not answer how the 'I' can come into play. According to Biesta, this is the case because the acquisition of new habits and knowledge in Dewey's theory of education is acquired by placing the human organism in new environments "as it is through interaction with such environments that human organisms acquire new habits and knowledge and hence learn" (p.7).

The educational theory of Dewey, as a paradigm case of cultivation, seems to support educational tasks as qualification and socialization, and can well 'explain' how Eichmann came to be the man he turned out to be, given the values and social context of his time. However, argues Biesta, the cultivation paradigm of education is unable to explain the case of Parks (p. 7). The kind of human being that the cultivation paradigm of education fosters, can be called 'bio-neuro-socio-cultural' (p. 4), building on intelligent adjustment to ever evolving environment conditions. This is an understanding of the human being in light of survival, maintains Biesta, but survival is not the same as life and indeed not the only 'modality' of human existence (p. 7).

I find that the understanding of the human being, fostered in the cultivation 'paradigm', bears a resemblance to Hacking's interpretation of the human being as an interactive kind. The paradigm imparts an understanding, able to tell the story of who we are primarily in light of different subject fields in sciences, as a coordinate between the system axis and the individual, interacting between culture and environment. Hacking (2007) holds that science

Footnote 4 (continued)

shot and burned by high school and college graduates. So, I am suspicious of education. My request is: Help your students become human. Your efforts must never produce learned monsters, skilled psychopaths, educated Eichmanns. Reading, writing and arithmetic are important only if they serve to make our children more humane" (Strom and Parsons 1994, pp. 519-520). I think the school principal's reflection is similar to the intention of the Parks-Eichmann case, which Biesta uncovers as a paradox from an educational angle. 
has been so central to the human understanding of who we are, that we create ourselves in our own scientific image of the kinds of people we can be (p. 305). With a touch of irony, MacIntyre (2009, p. 175) gives a summary of a scientific view on man from the angle of various disciplines (physics, chemistry, biology, history, economy, psychology, sociology and the arts), and with this he displays a scattered and fragmented view of what a human being is, from the angle of science. Seeing the human being primarily as an interactive combination of nature, nurture or technology (Cyborgs) does not bring about a platform for the main educational question, the question of subjectification. Rather these interactions shed light on the way in which humans are making up various identities. Hacking has coined the concept biosocial identity (2006, p. 81) which is close to Biesta's concept 'bio-neuro-socio-cultural'. Who we are and how we have become who we are, is a question of identity; the educational question, however, is about how an 'I' can step forward from all this; "how we try to live our own life, what we will do with who we have become" (Biesta 2020, pp. 4). The paradigm of cultivation encourages identity making, through interactions and understanding of ourselves as, bio-neuro-socio-cultural beings, while existential education challenges us to bring into play our "'subject-ness', our way of and our attempts at existing-as-subject of our own life, not as the object of influences from 'elsewhere"" (p. 5). The existential paradigm of education is thus the paradigm of the ' $I$ '. What makes this paradigm fundamentally different form the paradigm of cultivation, says Biesta is "that the ' $I$ ' is not the outcome of a process of cultivation and therefore not something that can be produced educationally (or to be more precise: that can be produced through cultivating work upon a 'thing')" (p. 8). With this distinction between a paradigm of cultivation and existence, Biesta has sought to distinguish between language that matters in terms of the theory and practice of education, which is very important as it determines the language of the person.

A short summary of the different paradigms follows. The paradigm of cultivation relates to many educational practices which we typically recognize as educational tasks, human flourishing, learning outcomes, developing opportunities and capacities, etc. Biesta's point is that a paradigm of cultivation is not sufficient on its own as it does not provide a framework for foregrounding the question of the 'I', the quest for subjectification. Cultivation, as an educational framework, primarily rests on an understanding of the human as a bioneuro-socio-cultural being, and thus does not manage to get outside its own premises, it is, in a way, locked up in a 'looping effect' of interactions (Hacking $2007^{5}$ ). In this web of interactions, the cultivation paradigm, is according to Biesta, unable to explain actions carried out by people who resist the 'cultural and social order', such as Rosa Parks. Implicit in the social order at that time, was an agreement that there should be different capability sets for racial minorities and white people. The freedom to choose areas, seats and a host of other things were dependent on skin colour. Rather than acknowledging this order Parks insisted on preserving her own self-respect, and she opposed the social structure. In order to explain such human actions, a paradigm of existence is essential, where the question of the ' $\mathrm{I}$ ' is foregrounded, encouraging the how of human life. Not who or what one is, but how one wants to live one's life, in relation to who one has become or to settle for whom one has turned out to be in order to also change that.

\footnotetext{
${ }^{5}$ Hacking refers to the 'looping effect' when he describes how scientific classification 'makes up people' in the process of classifications where he has identified several central steps. The looping effect is the interaction of this classification process (Hacking 2007, pp. 258, 288).
} 
I think the significance of foregrounding the ' $\mathrm{I}$ ' is vital regarding the issue of diversity as it relates to disability in relation to a host of fundamental issues as questions, such as various ability expectations dominant in the social and cultural setting, the instrumentalization of education, the emphasis on target-setting cultures and other accountability practices. Seeing the task of education and children from an existential paradigm, foregrounding the 'I', and not viewing them as a 'thing' which a teacher/parent shall cultivate, opens up different approaches regarding the question of diversity relating to disability and interpretations of educational challenges. When the focus is on opportunities to "exercise control in certain domains" (Begon 2017 pp. 155-156), one opens up the educational question of how one wants to live one's life, and not just emphasising opportunities to function informed by dominant norms and values. I believe that much of the critique regarding the enterprise of special education can be related to the task of education primarily being viewed as cultivation, where particular abilities and the achievement of specific functionings have been focused, often in combination with individual and medical interpretations of disability. This has especially been prevalent in the critique from the field of Disability Studies regarding special education (see Connor 2019; Gallagher et al. 2004). Emphasizing the paradigm of existence foregrounding the ' $\mathrm{I}$ ', is a step in the right direction in my view. It enables the language of education in education to exist and hence makes it possible to 'put persons back into education', which Pring (2012) is urging the field of education to instigate. However, a language of the person needs to be embedded in un understanding of what it is to be a person.

\section{Diversity and the Person-Being Someone Versus Being Something}

In the chapter "Personhood and the social inclusion of people with disabilities" Ikäheimo (2009) encourages us to deliberate on what it is to be a person and more specifically what it is to be a disabled person. He invites us to consider the question of whether impairments can compromise someone's personhood, or whether we are persons completely independent of our abilities, of what we can perform and do? (p. 77). To actualize these questions Ikäheimo invites us to contemplate a thought-experiment regarding how many persons there are in a room and in so doing, he attempts to illustrate the attribution humans undertake in relation to 'person-making significances.' He writes:

Case 1: You are in a room with an average, more or less healthy friend of yours. Count how many persons there are in the room. Quite obviously two?

Case 2: You are in a room with a healthy newborn human child. Count. One or two persons in the room?

Case 3: You are in a room with a human being lacking all higher brain functions due to innate malformations. One or two persons?

Case 4: You are in a room with a friend who has suffered massive brain injury in an accident and is in an irrecoverable coma. One or two?

Case 5: You suffer from a physical condition which gives you severe forced movements, makes it difficult for you to communicate with other people in any spoken language, and makes you dependent on a wheelchair to move and an assistant in daily life. But your mind is as bright as anyone's. Often among more or less healthy persons you have a vivid feeling that you do not fully count as a person (pp.78, 83-84). 
In order to shed light on these dissimilar cases Ikäheimo discusses different aspects of what he terms 'person-making significances' in relation to their objects, as he argues that it is these significances that make someone a person in the interpersonal sense, within concrete contexts of social life (p. 77). In his discussion relating to these various cases, Ikäheimo questions whether everyone will agree that there are two persons in the room, even though there may be no doubt that there are humans in the room (p. 78). He then investigates the different inclusion and exclusion mechanisms in the contexts of social life, and analyses different factors that influence these 'person-making significances.' Certain conclusions of his are as follows: "As to what I have called interpersonal personhood, or the interpersonal component of what it is to be a person in a full-fledged sense, it is simply a fact that many disabled people suffer from lack of it" (p. 88). That said, Ikäheimo stresses the importance of highlighting this fact by helping them lead their lives as fully as they can as persons among other persons (p. 88). Ikäheimo's thought experiment illustrates how the status of being a person might be attributed relative to contexts and ability expectations in social life. His case 5 is often described in the literature, written by people with different impairments. In these texts people with impairments put words to feelings of not being reckoned among equals because they lack abilities expected to be performed by persons and therefore have a sense of not having the same personal status as other persons who do not lack certain abilities (see O'Brian with Kendall 2003, p. 4). The aforementioned cases illustrate a problem that Spaemann $(2006,2010$, 2015) has dealt with in light of his distinction between being 'someone' versus being 'something'. These cases suggest that there is a common understanding that a difference exists between being a human being and being a person, and that being a person is something that one 'acquires' through 'personmaking significances' in a community of recognition. The five cases also allude to the fact that there is a degree of difference between being a fully-fledged person and something less. The fact that there are different attitudes to people and that people are treated differently from an economical, legal and ethical perspective is well documented in research, but that should not imply that personal status is associated with acceptance. Spaemann (2006) argues that there has been a shift in recent years on the thinking with regard to the concept of person. He writes that the term 'person' has, since Boethius' famous definition of the person as 'the individual substance of rational nature', been a discussion within philosophy to identify attributes that licence us to apply the terms to certain beings (p. 1). Since Kant, the term 'person' has, according to Spaemann, served as a nomen dignitatis, an evaluative concept which has acted as a foundation for human rights (p. 2). However, something has changed more recently in the order of logic. Spaemann writes:

Now its function has been reversed. Suddenly the term 'person' has come to play a key role in demolishing the idea that human beings, qua human beings, have some kind of rights before other human beings. Only human beings can have human rights, and human beings can have them only as persons. The argument then runs: but not all human beings are persons, and those that are, are not persons in every stage of life or in every state of consciousness. They are not persons if from the first moment of their lives they are refused admission to the community of recognition, for that is what makes human beings persons (his italics p. 2).

Demonstrating a change in the order of logic, as Spaemann illustrates in the above citation, is I will argue, exemplified by the aforementioned five cases in Ikäheimo's thoughtexperiment. These cases illustrate the issue of making a distinction between being a human and being a person. Spaemann does not agree that it is possible to make such a distinction. In his view, all human beings are persons because persons are 'individuals' in an 
unparalleled sense, not by their individual demonstration of specific features, but simply by their membership of the species from the beginning (p. 3). He dismisses that there should be any qualifications, 'person-making significances', that one develops or loses. To be a person is the framework of being a human being, persons are the mode in which a human being exists, it is amodus existendi (p. 237). Spaemann argues, that the thinking that persons are 'something' that becomes 'someone' by recognition, because of the ownership of 'rational nature', goes back to Locke and is currently argued by Singer and others (p. 252). The consequence of such a view is that human beings are not fully regarded as persons if they do not execute abilities that are typically recognized as powers of rationality and intentionality. This has been documented in the history of intellectual disability (Carlson 2009; Paul 1998). The view of the person, represented by Locke, Singer and others, is, according to Spaemann, based on the thinking that one does not enter the community by being begotten or born, but by becoming self-aware and being co-opted by other members (2006 p. 238). This position is untenable, according to Spaemann, ${ }^{6}$ for several reasons. Firstly, we never consciously 'make' persons. We do not for example start to talk to a child as a thing and then alter our communication to the child as someone. The child is already someone when addressed, although it takes some time before a child starts to say 'I'. Spaemann states: "But what does he or she mean by 'I'? Not 'an I', but simply the selfsame human being who says 'I'" (his italics p. 245). Personality is not developed but the framework. There is just one criterion for personality, according to Spaemann, and that is biological membership of the human race (p. 247). I think the position Spaemann takes is very important considering the issue of diversity with regard to disability, as those with impairments are often used as examples in theories which maintain that personal existence is conferred by recognition and consequently, those with impairments are regularly ostracized from the community of recognition, as the history of disability has showed. This is still the case, as is documented through statistics on children with impairments who are out of school (UNESCO 2020 pp.71).

\section{Concluding Remarks}

The overall argument in the article is built on an acknowledgement of Pring's argument, that there is a 'depersonalization' process in education. Recognizing this trend, I have argued that a language of diversity related to disability and educational challenges should be embedded in a language of the person, being someone. In order to support such an idea, I have presented three distinctions: disability and impairment, paradigm of cultivation versus an existential educational paradigm and the distinction between being someone and being something. I suggested that diversity related to disability, should be interpreted within a social relational model of disability, within the framework of an adjusted capabilities approach, emphasizing capability as an opportunity to control certain domains, rather than an opportunity to function. Begon's adjustment of the capabilities approach, I argued, shifted the emphasis to an 'I', rather than a preoccupation with functionings. However, this does not mean that achieving functionings should not be emphasized, rather the issue is the order of things that gives importance to the fulcrum of educational practice. This was

\footnotetext{
${ }^{6}$ Spaemann lists six reasons for building his argument in order to show the intuitive conviction that all human beings are persons (see Spaemann 2006. "Are all Human Beings Person?" pp. 236-248).
} 
pointed out by Biesta's distinction between the two different educational paradigms, and the importance of an existential paradigm foregrounding the ' $\mathrm{I}$ ', as well as the emphasis on the question of how in education. Nonetheless, when foregrounding the ' $\mathrm{I}$ ' is underscored, I argued that it is pivotal to recognize in which understanding of the person the ' $I$ ' is embedded. Here, it was suggested, that an understanding of the person should be founded in Spaemann's interpretation of being a person-embedded in the mode in which a human being exists, a modus existendi-and not as 'something' that becomes 'someone' by recognition. Spaemann's distinction was important, I argued, in order to oppose the emphasis on an ever-increasing ability expectation that is often highlighted by advocates of enhancement (Buchanan 2011ab). If being a person is dependent on recognition, by achieving functionings that reflect dominant norms and values, enhancement and cures might be developed into a requirement for being included. However, if diversity related to disability is embedded in an understanding of the person as modus existendi, where being a person does not lie in an understanding of developing 'person-making significances', but is resting in the framework of being a human, I argue that this will underscore a value-neutral account of physical and cognitive differences. Emphasising the person as someone, and not as something that shall be cultivated on, opens the ground for the how in education, enabling a language of the person who exists and stands for the challenge to lead his or her own life.

Open Access This article is licensed under a Creative Commons Attribution 4.0 International License, which permits use, sharing, adaptation, distribution and reproduction in any medium or format, as long as you give appropriate credit to the original author(s) and the source, provide a link to the Creative Commons licence, and indicate if changes were made. The images or other third party material in this article are included in the article's Creative Commons licence, unless indicated otherwise in a credit line to the material. If material is not included in the article's Creative Commons licence and your intended use is not permitted by statutory regulation or exceeds the permitted use, you will need to obtain permission directly from the copyright holder. To view a copy of this licence, visit http://creativecommons.org/licenses/by/4.0/.

\section{References}

Arnesen, Anne-Lise., Reetta Mietola, and Elina Lahelma. 2007. Language of inclusion and diversity: Policy discourses and social practices in finnish and Norwegian schools. International Journal of Inclusive Education 11: 97-110. https://doi.org/10.1080/13603110600601034.

Barnes, Elizabeth. 2016. The minority body: A theory of disability. Oxford: Oxford University Press.

Barnes, Elizabeth. 2018. Against impairment: Replies to Aas, howard, and Francis. Philosophical Studies 175: 1151-1162.

Begon, Jessica. 2017. Capabilities for all?: From capabilities to function, to capabilities to control. Social Theory and Practice 43: 154-179.

Begon, Jessica. 2020. Disability: A justice-based account. Philosophical Studies. https://doi.org/10.1007/ s11098-020-01466-3.

Benjamin, Shereen. 2002. "Valuing diversity": A cliché' for the 21st century? International Journal of Inclusive Education 6: 309-323.

Biesta, Gert J. J. 2006. Beyond learning democratic education for a human future. Boulder, CO: Paradigm.

Biesta, Gert. 2012. Philosophy of education for the public good: Five challenges and an agenda. Educational Philosophy and Theory 44: 581-593.

Biesta, Gert. 2020. Can the prevailing description of educational reality be considered complete? on the Parks-Eichmann paradox, spooky action at a distance and a missing dimension in the theory of education. Policy Futures in Education. https://doi.org/10.1177/1478210320910312.

Bostrom, Nick, and Anders Sandberg. 2009. Cognitive enhancement: Methods, ethics, regulatory challenges. Science and Engineering Ethics 15: 311-341. 
Buchanan, Allen. 2011a. Better than human: The promise and perils of enhancing ourselves. New York: Oxford University Press.

Buchanan, Allen. 2011b. Cognitive enhancement and education. Theory and Research in Education 9: $145-162$.

Carlson, Licia. 2009. The faces of intellectual disability: Philosophical reflections. Bloomington: Indiana University Press.

Connor, David J. 2019. Why is special education so afraid of disability studies? Analyzing attacks of disdain and distortion from leaders in the field. Journal of Curriculum Theorizing 34: 10-23.

Felder, Franziska. 2019. Celebrating diversity in education and the special case of disability. Educational Review. https://doi.org/10.1080/00131911.2019.1576590.

Fricker, Miranda. 2017. Evolving concepts of epistemic injustice. In Routledge Handbook of Epistemic Injustice Routledge Handbooks in Philosophy, eds. Ian James Kidd, José Medina and Gaile Pohlhaus, 53-60. London: Routledge.

Gallagher, Deborah J., Lous Heshusius, Richard P. Iano, and Thomas M. Skrtic. 2004. Challenging orthodoxy in special education: Dissenting voices. Denver, CO: Love.

Hacking, Ian. 2006. Genetics, biosocial groups \& the future of identity. Daedalus 135: 81-95.

Hacking, Ian. 2007. Kinds of people: Moving targets. In Proceedings-British Academy 151: 285-318. Oxford: Oxford university press inc.

Hinchcliffe, Geoffrey, and Lorella Terzi. 2009. Introduction to the special issue 'Capabilities and education.' Studies in Philosophy and Education 28: 387-390.

Ikäheimo, Heikki. 2009. Personhood and the social inclusion of people with disabilities. In Arguing about disability philosophical perspectives, ed. Kristjana Kristiansen, Tom Shakespeare, and Simo Vehmas, 77-92. London: Routledge.

Kiuppis, Florian. 2014. Why (not) associate the principle of inclusion with disability? tracing connections from the start of the 'Salamanca process.' International Journal of Inclusive Education 18: 746-761.

Lipstadt, Deborah E. 2011. The Eichmann Trial. Jewish Encounters. New York: Nextbook Schocken.

MacIntyre, Alasdair. 2009. God, philosophy, universities: A selective history of the Catholic philosophical tradition. Lanham: Rowman \& Littlefield.

Nussbaum, Martha C. 2006. Frontiers of justice: disability, nationality, species membership. Cambridge, MA: Belknap press of Harvard University Press.

Nussbaum, Martha C. 2011. Creating capabilities. Cambridge, MA: Belknap Press of Harvard University Press.

O'Brien, Mark with Gillian Kendall. 2003. How I Became a Human Being: A Disabled Man's Quest for Independence, Wisconsin Studies in Autobiography. Madison, Wisconsin: The University of Wisconsin Press.

Oliver, Mike. 1996. Defining impairment and disability. Issues at stake. In Exploring the divide: Illness and disability, eds. Colin Barnes and Geof Mercer, 39-54. Leeds: Disability Press.

Paul, Diane B. 1998. The politics of heredity essays on eugenics, biomedicine, and the nature-nurture debate. Albany: State University of New York Press.

Pring, Richard. 2012. Putting persons back into education. Oxford Review of Education 38: 747-760.

Reindal, Solveig M. 2008. A social relational model of disability: A theoretical framework for special needs education? European Journal of Special Needs Education 23: 135-146.

Reindal, Solveig M. 2009. Disability, capability, and special education: Towards a capability-based theory. European Journal of Special Needs Education 24: 155-168.

Reindal, Solveig M. 2010. Redefining disability: A rejoinder to a critique. Etikk i praksis-Nordic Journal of Applied Ethics 1: 125-135.

Reindal, Solveig M. 2016. Discussing inclusive education: An inquiry into different interpretations and a search for ethical aspects of inclusion using the capabilities approach. European Journal of Special Needs Education 31: 1-12.

Riddle, Christopher A. 2013. Defining disability: Metaphysical not political. Medicine, Health Care and Philosophy 16: 377-384.

Scully, Jackie L. 2012. Deaf Identities in disability studies: With us or without us? In Routledge handbook of disability studies, ed. Nick Watson, Alan Roulstone, and Carol Thomas, 109-122. New York: Routledge.

Sen, Amartya. 1992. Inequality reexamined. New York: Russell Sage Foundation.

Sen, Amartya. 2009. The idea of justice. London: Allen Lane.

Spaemann, Robert. 2006. Persons: The difference between "someone" and "something." Oxford: Oxford University Press.

Spaemann, Robert. 2010. Essays in anthropology: variations on a theme. Trans. Guido de Graff and James Mumford. Eugene Oregon: Cascade books. 
Spaemann, Robert. 2015. A Robert Spaemann reader: philosophical essays on nature, God, and the human person. Eds \& trans. D. C. Schindler and Jeanne H. Schindler. Oxford: Oxford University Press.

Strom, Margot S., and William S. Parsons. 1994. Facing history and ourselves: Holocaust and human behavior. Watertown, MA: Intentional Educations.

Taylor, Ashley. 2012. Addressing ableism in schooling and society? The capabilities approach and students with disabilities. Philosophy of Education Archive, 113-121.

Terzi, Lorella. 2004. The social model of disability: A philosophical critique. Journal of applied philosophy 21: 141-157.

Terzi, Lorella. 2005a. A capability perspective on impairment, disability and special needs: Towards social justice in education. Theory and Research in Education 3: 197-223.

Terzi, Lorella. 2005b. Beyond the dilemma of difference: The capability approach to disability and special educational needs. Journal of Philosophy of Education 39: 443-459.

Terzi, Lorella. 2008. Justice and equality in education a capability perspective on disability and special educational needs. New York: Continuum.

Theoharis, Jeanne. 2015. The Rebellious Life of Mrs. Rosa Parks. Boston: Beacon Press.

Thomas, Carol. 2004. How is disability understood? An examination of sociological approaches. Disability and Society 19: 569-583.

Thomas, Carol. 2007. Sociologies of disability and illness: Contested ideas in disability studies and medical sociology. Houndmills: Macmillan International Higher Education.

United Nations Educational, Scientific and Cultural Organization (UNESCO). 2020. Global education monitoring report 2020: inclusion and education: all means all.

Vehmas, Simo and Pekka Mäkelä. 2009. The ontology of disability and impairment. A discussion of the natural and social features. In Arguing about disability philosophical perspectives, eds. Kristjana Kristiansen, Tom Shakespeare and Simo Vehmas, 42-57. London: Routledge.

Vehmas, Simo, and Nick Watson. 2016. Exploring normativity in disability studies. Disability \& Society 31: 1-16. https://doi.org/10.1080/09687599.2015.1120657.

Wolbring, Gregor. 2012. Ethical theories and discourses through an ability expectations and ableism lens: The case of enhancement and global regulation. Asian Bioethics Review 4: 293-309.

Publisher's Note Springer Nature remains neutral with regard to jurisdictional claims in published maps and institutional affiliations. 